\title{
Wild chimpanzees deprived a leopard of its kill: Implications for the origin of hominin confrontational scavenging
}

\section{AUTHOR(S):}

Nakamura, Michio; Hosaka, Kazuhiko; Itoh, Noriko; Matsumoto, Takuya; Matsusaka, Takahisa; Nakazawa, Nobuko; Nishie, Hitonaru; ... Takahata, Yukio; Yamagami, Masahiro; Zamma, Koichiro

\section{CITATION:}

Nakamura, Michio ... [et al]. Wild chimpanzees deprived a leopard of its kill: Implications for the origin of hominin confrontational scavenging. Journal of Human Evolution 2019, 131: $129-138$

\section{ISSUE DATE:}

2019-06

\section{URL:}

http://hdl.handle.net/2433/240959

\section{RIGHT:}

(C) 2019. This manuscript version is made available under the CC-BY-NC-ND 4.0 license

http://creativecommons.org/licenses/by-nc-nd/4.0/.; The full-text file will be made open to the public on 01 June 2020 in accordance with publisher's 'Terms and Conditions for Self-Archiving'.; This is not the published version. Please cite only the published version.; この論文は出版社版でありません。引用の際には出版社版をご確認ご利用ください。 
NOTICE: This is the author's version of the following article.

Nakamura M, Hosaka K, Itoh N, Matsumoto T, Matsusaka T, Nakazawa N, Nishie H, Sakamaki T, Shimada M, Takahata Y,

Yamagami M, Zamma K 2019. Wild chimpanzees deprived a leopard of its kill: Implications for the origin of hominin

confrontational scavenging. Journal of Human Evolution 131: 129-138. DOI: 10.1016/j.jhevol.2019.03.011

(C) Elsevier. The original publication is available on http://www.elsevier.com/locate/jhevol/.

\title{
Wild Chimpanzees Deprived a Leopard of Its Kill: Implications for the Origin of Hominin Confrontational Scavenging
}

\author{
Michio Nakamura ${ }^{\mathrm{a}}$, Kazuhiko Hosaka ${ }^{\mathrm{b}}$, Noriko Itoh ${ }^{\mathrm{a}}$, Takuya Matsumoto ${ }^{\mathrm{c}, \mathrm{d}}$, Takahisa \\ Matsusaka $^{\mathrm{e}}$, Nobuko Nakazawa ${ }^{\mathrm{a}}$, Hitonaru Nishie ${ }^{\mathrm{a}, \mathrm{d}}$, Tetsuya Sakamaki ${ }^{\mathrm{a}}$, Masaki \\ Shimada $^{\mathrm{f}}$, Yukio Takahata ${ }^{\mathrm{g}}$, Masahiro Yamagami ${ }^{\mathrm{a}}$, and Koichiro Zamma ${ }^{\mathrm{h}}$
}

\footnotetext{
${ }^{a}$ Kyoto University, Japan

b Kamakura Women's University, Japan

c The Research Institute for Humanity and Nature, Japan

d JSPS Research Fellow

e Osaka Seikei University, Japan

${ }^{\mathrm{f}}$ Teikyo University of Science and Technology, Japan

g Kwansei Gakuin University, Japan

${ }^{\mathrm{h}}$ Nagano College of Nursing, Japan
}

\begin{abstract}
This study reports the first observed case of wild chimpanzees (Pan troglodytes) obtaining animal prey freshly killed by a sympatric leopard (Panthera pardus) and scavenging it with the leopard still nearby. This observation has important implications for the emergence of confrontational scavenging, which may have played a significant role in human evolution. Many scholars agree that eating meat became important during human evolution, and hominins first obtained meat by scavenging. However, it is debatable whether scavenging behavior was "passive" or "confrontational (power)." The latter is more dangerous, as it requires facing the original predator, and it is thus considered to have been important for the evolution of several human traits, including cooperation and language. Chimpanzees do scavenge meat, although rarely, but no previous evidence of confrontational scavenging has hitherto emerged. Thus, it was assumed that they are averse to confrontation with even leopard-sized predators. However, in the observed case the chimpanzees frequently emitted waa barks, which indicated that they were aware of the leopard's presence but they nevertheless continued to eat the scavenged meat. In addition, we compiled and reviewed 49 cases of chimpanzee encounters with animal carcasses in the Mahale Mountains of Tanzania in 1980-2017. Chimpanzees scavenged meat in $36.7 \%$ of these cases, and tended to eat the meat when it was fresh or if the animal species was usually hunted by chimpanzees. However, no evidence indicated that carcasses were avoided when leopard involvement was likely. These results suggest that chimpanzee-sized hominins could potentially confront and deprive leopard-size carnivores of meat.
\end{abstract}

Keywords: chimpanzee; confrontational scavenging; leopard; animal carcass; Mahale Mountains; meat-eating

\section{Introduction}

Eye-catching terms such as “confirmed killer" (Dart, 1953), "killer ape” (Ardrey, 1961), or "man the hunter" (Lee and De Vore, 1968), reflected a prevailing assumption that large game hunting began soon after the hominin lineage diverged from other African 
apes. Several human traits were thought to have arisen in early hominins in association with hunting or in order to enable it. This hypothesis is no longer widely accepted because it seems unlikely that australopithecines, who were equipped with approximately chimpanzee-sized brains and bodies, could hunt large game without (or with only rudimentary) tools. However, increased meat consumption is still thought to have played a significant role in the course of human evolution (e.g., Speth, 1989; Kennedy, 2005).

Many recent scholars hypothesize that hominins began obtaining meat by scavenging, sometime around the transition from the Pliocene to the Pleistocene (Shipman, 1986; Blumenschine, 1987). Simple stone tools may have worked well for scavenging rather than for hunting. Investigations of cut or percussion marks from hominin tools and carnivore tooth marks on the bones of prey animals led some researchers to argue that carnivores accessed the carcasses first (e.g., Blumenschine, 1995; Blumenschine et al., 2007; Pante et al., 2012, 2015). Others have argued that hominins accessed carcasses first, with carnivores scavenging the remains afterwards (Domínguez-Rodrigo and Barba, 2006, 2007; Domínguez-Rodrigo et al., 2014).

The scavenging hypothesis raises the question of whether early hominin scavenging behavior was "passive" (Blumenschine, 1995; Pante et al., 2012) or "confrontational (power)" (Bunn and Kroll, 1986; Bunn and Ezzo, 1993; Bunn, 2001; O'Connell et al., 2002). In passive scavenging, hominins would have obtained a carcass after the original predators had completed eating and had left the vicinity of the carcass. Hominins would then have scraped the leftover meat that still adhered to surface of the bones and accessed the marrow by cracking open the bones. In confrontational scavenging, however, hominins would have chased away the original predators to obtain the still-meaty carcass. It should also be emphasized that meat obtained in this way would have been much fresher and thus safer to eat due to the lower risk of bacterial infection than meat obtained by passive scavenging. However, confrontational scavenging would also have been more dangerous for hominins because it would require facing the original predator.

Confrontational scavenging is observed in contemporary hunter-gatherers. For example, in some seasons, the Hadza people were reported to obtain $20 \%$ of their meat through confrontational scavenging (O'Connell et al., 1988), and the San people also often deprive large carnivores of their kills (Tanaka, 1990). Both of these peoples find carcasses by following signs of flying vultures and rush there to obtain the meat. Confrontational scavenging is not limited to hunter-gatherers, though: Ugandan farmers also opportunistically chase away large carnivores to obtain meat (Treves and Naughton-Treves, 1999). 
As reviewed by Moleón et al. (2014), the transition to meat, probably first obtained through scavenging, drastically changed many hominin behaviors. The development of confrontational scavenging is often regarded as an important step in the evolution of several human traits. For example, some researches argue that because this niche requires numerical superiority against original predators, it may have led to the development of cooperation and language. This would have occurred because communicating the location of a carcass to others and recruiting them to the location would be greatly advantageous (Bickerton, 2009; Bickerton and Szathmáry, 2011).

It is important to estimate the time when regular scavenging may have begun in the course of human evolution. Early Pleistocene assemblages of animal bones, such as FLK Zinji, are usually regarded as evidence of regular scavenging by early Homo, whether passive or confrontational. However, some researchers such as Bunn and Gurtov (2014) have argued, based on their analyses on prey mortality profiles, that early Homo were probably ambush hunters. If this is correct, and if we assume that scavenging preceded hunting, then regular scavenging for meat could have begun much earlier, possibly among the australopithecines.

\subsection{Relationship between hominins and carnivores}

There is a common notion that contemporary humans are no longer preyed upon by large carnivores. Louis Leaky once commented that "we are not cat food" (Strauss, 1972). More recently, some researchers have affirmed that modern humans are no longer preyed upon by felines (Poirotte et al., 2016). This may be true for city dwellers, who are not sympatric with big cats, but a large number of reports indicate that contemporary humans in other habitats are hunted and eaten by them (Treves and Naughton-Treves, 1999; Yamazaki and Bwalya, 1999; Kerbis Peterhans and Gnoske, 2001; Hart and Sussman, 2005; Baldus, 2006). These incidents have occurred long after the invention of advanced weapons such as firearms and more secure physical shelters such as houses: it is therefore not unreasonable to assume that before these technologies were available Homo sapiens and earlier Homo probably suffered much higher rates of predation. Therefore, the relationship between humans and carnivores is not simple: humans are susceptible to predation by predators, although they can actively chase the same predators away and obtain their kills.

The smaller bodies and less efficient weapons of Pliocene hominins likely rendered them even more vulnerable to predation by large felids than later hominins (Hart and Sussman, 2005). This raises the questions of whether Pliocene hominins were able to chase away carnivores to obtain meat. The relationships between contemporary nonhuman hominids and carnivores should serve as a good model for addressing this 
question. Chimpanzees (Pan troglodytes) are good candidates for modelling early hominins in this context, as they are smaller than humans and lack sophisticated projectile weapons, while they also regularly capture and eat other mammals (Hosaka, 2015).

\subsection{Relationships between chimpanzees and carnivores}

Although a few reports of chimpanzee encounters with lions (Panthera leo) (Tsukahara, 1993) and wild dogs (Lycaon pictus) (McLester et al., 2016) exist, these large carnivores are not usually sympatric with the chimpanzee. For chimpanzees, the leopard (Panthera pardus) seems to be the most significant predator among all large African carnivores. This is because its distribution largely overlaps with that of the chimpanzee, and there have been several reports of encounters between these two species (see reviews by Boesch, 2009; Pierce, 2009; Nakazawa et al., 2013).

In forested environments, primates are often major prey of leopards, and predation pressure by leopards is regarded as having been a significant factor in the evolution of forest primates (Zuberbühler and Jenny, 2002; Klailova et al., 2013). Chimpanzees are likewise potential leopard prey, and there is both direct and indirect evidence that chimpanzees are eaten by leopards (e.g., Boesch, 1991; Nakazawa et al., 2013). Even though the frequency of actual predation in chimpanzees appears to be low, this predation pressure could have led to the formation of sociality and reciprocity, or cooperation, in chimpanzees (Boesch, 2009). Upon encountering a leopard, chimpanzees may ignore it, become restless, become alarmed, throw something, or make a fuss (Izawa and Itani, 1966; Kortlandt, 1967; van Lawick-Goodall, 1968; Nishida, 1968; Gandini and Baldwin, 1978; Pierce, 2009; Hosaka and Ihobe, 2015; Nishie, 2018). In extreme cases, chimpanzees have been reported to attack and kill leopard cubs (Hiraiwa-Hasegawa et al., 1986; Boesch, 2009).

\subsection{Scavenging by wild chimpanzees}

Wild chimpanzees are known to scavenge meat, but only rarely. Watts (2008) reviewed 24 cases of scavenging from four long-term study sites of chimpanzees (Gombe, Mahale, Taï, and Ngogo) and provided details of four cases he observed at Ngogo. Scavenged animals were mostly monkeys and small duikers but included some larger species such as bushbucks and bushpigs. After the publication of this review, another report was published indicating that chimpanzees ate duikers captured in human traps (Brand et al., 2014). However, these were not cases of scavenging in the strict sense because the duikers were still alive. 
The cases reviewed by Watts (2008) that were suggestive of scavenging of carnivore kills were nearly all limited to Mahale, in East Africa. There, chimpanzees sometimes scavenged carcasses that were likely to have been killed by leopards (Hasegawa et al., 1983; Nishida, 1994, 2012). Outside Mahale there was only one such case reported at Gombe, wherein chimpanzees mouthed a small portion of a bushbuck (Tragelaphus scriptus) carcass that had likely been killed by a leopard (Muller et al., 1995).

Watts (2008) concluded that "confrontational carcass theft" by chimpanzees is only applicable to cases of theft from olive baboons at Gombe (Morris and Goodall, 1977) and from the crowned-hawk eagles (Stephanoaetus coronatus) at Taï (Boesch and Boesch-Achermann, 2000: p. 170). Both are cases of confrontation against much smaller species that do not prey on chimpanzees. These interactions are not comparable to confrontational scavenging by early hominins of large carnivores' kills. Researchers in Mahale did note that in some cases, chimpanzees may have actually chased away leopards before they scavenged (Hasegawa et al., 1983; Nishida, 1994). However, these observations were not included in the cases of confrontational carcass theft discussed by Watts (2008) because the presence of leopards was unconfirmed. Thus, he concluded that "Observed cases of scavenging kills made by leopards ... did not involve confrontation" (Watts, 2008: 130). Studies that rely on this influential review often assume that chimpanzees are averse to confrontations with leopard-sized predators (Számadó, 2010).

Herein, we report the first observation of wild chimpanzees depriving a leopard off of its kill and eating the carcass with the leopard still in the vicinity. Additionally, we compiled and reviewed 49 cases of chimpanzee encounters with animal carcasses at Mahale in 1980-2017 to investigate the conditions under which chimpanzees scavenge meat.

\section{Materials and methods}

\subsection{Behavioral observation}

The subjects of this study were wild chimpanzees of the M group at the Mahale Mountains National Park, Tanzania. Research on chimpanzees has been ongoing at Mahale since 1965 (Nakamura et al., 2015); thus, all members of the M group are wellhabituated to human presence and can be individually identified. At the time of observation, the $\mathrm{M}$ group consisted of 62 chimpanzees, including 9 adult males, 21 adult females, and 32 immatures (infants to adolescents). On November 15, 2016, M.N. and M.Y. engaged in focal following of an adult female, Christina, beginning in the morning preceding the observed scavenging episode described in detail below. When 
we observed that Christina had obtained a duiker carcass and chimpanzees had begun eating the meat, we stopped following Christina specifically and began to follow the holders of the duiker carcass to record the meat consumption completely. We eventually collected the carcass.

The observation conducted was noninvasive, and our study complied with all Japanese institutional requirements, all Tanzanian regulations, and the Code of Best Practices for Field Primatology published by the International Primatological Society, following ethical best practices for the treatment of subjects in the field.

\subsection{Compilation of data on encounters with animal carcasses}

We collected published and unpublished observations of the Mahale M-group chimpanzees' encounters with any animal carcasses (with the exception of chimpanzee carcasses) between 1980 and 2017. We excluded chimpanzee carcasses because chimpanzees are not known to eat meat of adult conspecifics. Although cannibalism of infants does sometimes occur (e.g., Suzuki, 1971), it is usually associated with infanticidal attacks, and the underlying mechanism may be quite different from the consumption of the carcasses of other animal species. Whenever possible, we included information on the animal species, the age-class of the animal, the freshness of the carcass, and whether or not the chimpanzees scavenged (consumed meat from the carcass). We also recorded other notable responses of the chimpanzees, such as touching the carcass or emitting fearful vocalizations. Because of the rareness of the events, these observations were made ad libitum. Thus, the scavenging ratio presented herein may be inflated because researchers might have taken note of encounters when chimpanzees eventually ate carcasses more often than when the chimpanzees ignored them.

Alternatively, it is possible that the given scavenging ratio is an underestimation because when chimpanzees are found eating fresh meat, researchers tend to think that they captured the animal themselves. However, if we acknowledge that chimpanzees can deprive other predators of a kill, then it is possible that a fresh carcass could be obtained in this way before the observer arrives at the scene.

We grouped these cases according to the following three indicators: 1) whether the carcass was a chimpanzee food species, based on whether it has been reported to be hunted multiple times in the long-term records of the hunting and meat-eating activities of the Mahale chimpanzees (Hosaka et al., 2001); 2) whether the carcass was fresh (that is, it had not yet begun decomposing); and 3) whether any signs indicative of leopard involvement (e.g., canine marks or leopard vocalizations) were found. In some cases, some of the above information was not available (see Table 1 for details). 


\subsection{Statistical analyses}

The Fisher's exact test was used to determine whether the proportions of scavenging differed significantly in relation to the three binominal variables described in the previous section (food species, fresh carcass, and leopard involvement). This test was performed three times on the same dataset, with p-values adjusted following Benjamini and Hochberg's (1995) procedure. The alpha level was set at 0.05. All statistical tests were performed using R version 3.3.3 (R Core Team, 2017).

\section{Results}

\subsection{Observation of scavenging}

On November 15, 2016, M.N. and M.Y. had been observing the M group of chimpanzees since $7 \mathrm{~h} 57$ in the morning. At 11h00, a research assistant noticed that a leopard was sitting in the nearby bush while we observed some female chimpanzees in trees. The leopard quietly moved northward away from the chimpanzees, and they did not seem to notice it. We assumed that an adolescent female first noticed the presence of the leopard at 11h26 due to the waa barks (sensu Schel et al., 2013) she began to emit while moving northward through the tree branches. After some time elapsed, another chimpanzee, approximately $50 \mathrm{~m}$ eastward from us, began to emit waa barks $>15$ times, intermittently; thus, we assumed that the leopard had moved eastward. No other chimpanzees in the trees attempted to move.

At $12 \mathrm{~h} 05$, when the alpha male, Primus, arrived beneath the trees, the females descended and joined him. They barked loudly and hurried eastward in the direction of the waa barks that had been emitted by the other chimpanzee. Four minutes later, the chimpanzees arrived at a large Pseudospondias microcarpa tree and climbed it. An adult female, Zola, was already seated in the tree; thus, we assumed she had been the source of the waa barks. All of the chimpanzees then moved toward the branch on the northeast side and looked down at the ground which was covered with thick bush, meaning that we could not observe anything through it.

An adult female, Christina, climbed down the tree at $12 \mathrm{~h} 14$ and quickly moved into the bush which the chimpanzees had been looking at. She then brought out a carcass of a blue duiker (Philantomba monticola) that was almost intact, with the exception of wounds on its throat that may have been caused by leopard canines

(Christina did not bite the duiker or cause the wounds; Fig. 1a). She then climbed the tree with the carcass, sniffed it, and soon released it and let it fall to the ground. 

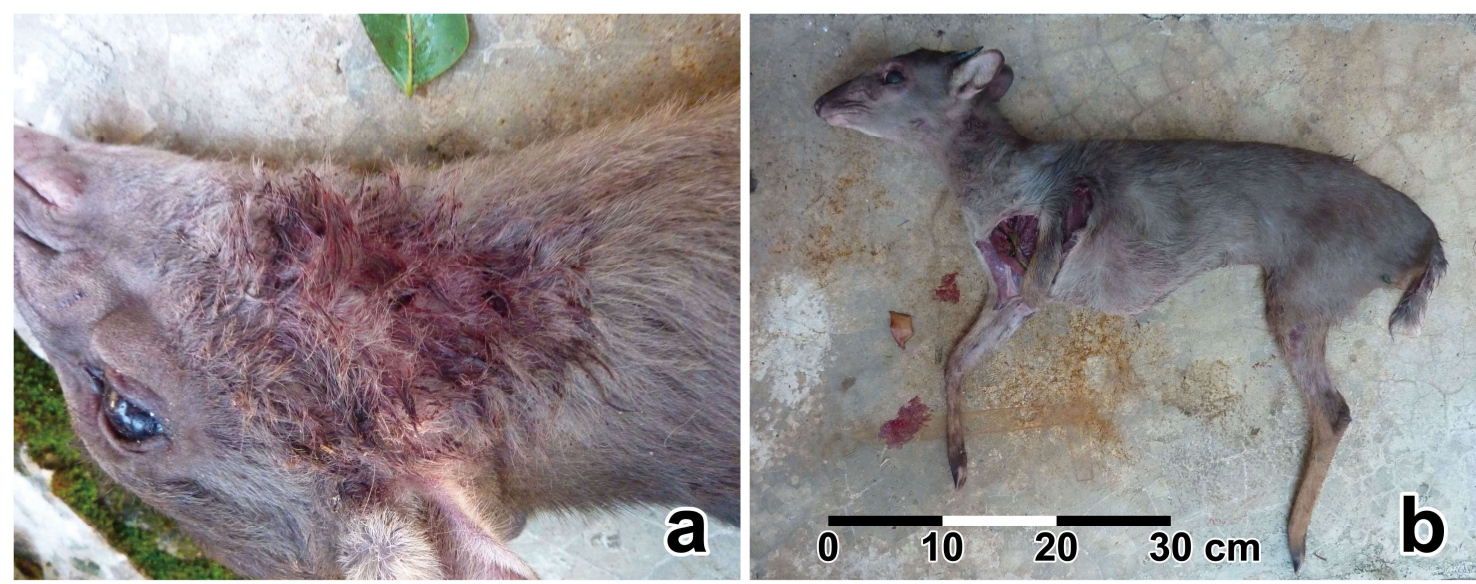

Figure 1. The blue duiker carcass collected after chimpanzees completely abandoned it (a) Close-up of the cervical region. Two wounds likely made by leopard canines can be seen on the throat.

(b) Full body. The left foreleg, right hind leg, and intestines are missing (either eaten or discarded by the chimpanzees), but other parts are mostly intact.

At $12 \mathrm{~h} 24$, the alpha male, Primus, descended to the ground and pulled the duiker back into the tree. He sat on a large bough and inspected the carcass, while Zola and Christina were approaching him. Blood was still oozing from the duiker's throat, and Primus took some time to investigate the abdomen with his fingers and mouth. During this time, we were able to observe the duiker's fully descended testes and thus identify it as an adult male.

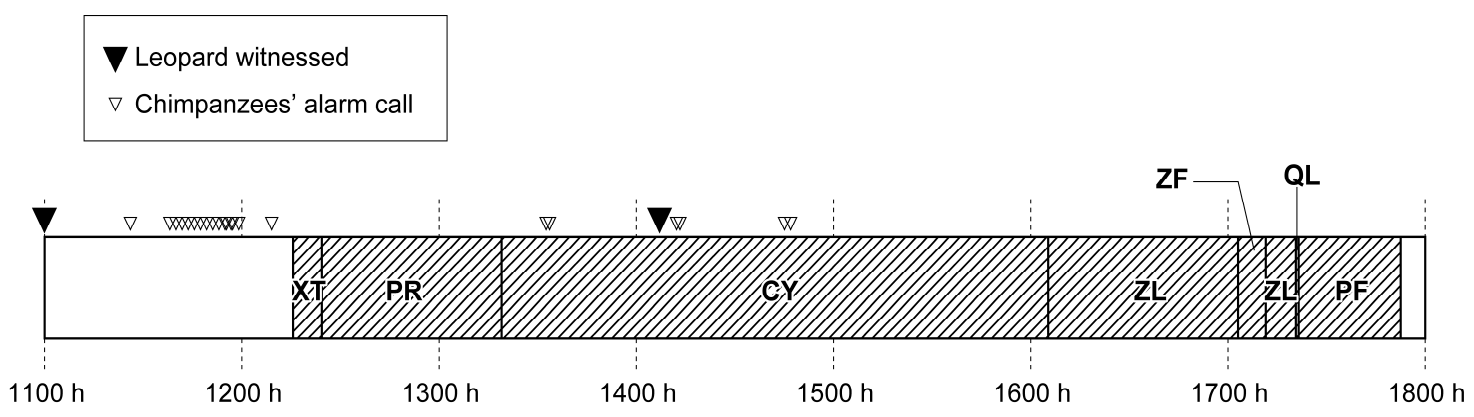

Figure 2. The time sequence of the observed scavenging episode (11h00 to $18 \mathrm{~h} 00$ )

The shaded parts indicate the times when chimpanzees were holding and eating the blue duiker carcass. The two capital letters indicate the abbreviated names of the carcass holders. The leopard's presence and the chimpanzees' calls (mostly waa barks) are also plotted at the top of the bar.

The abbreviations of chimpanzee names are as follows: XT, Christina (cycling adult female); PR, Primus (the alpha male); CY, Cynthia (lactating adult female); ZL, Zola (lactating adult female); ZF, Zorufa (adolescent female, Zola's daughter); QL, Quilt (adolescent female); PF, Puffy (lactating adult female). 
Primus scratched the abdomen until the intestine was exposed at $12 \mathrm{~h} 31$, at which point he began eating. The chimpanzees continued to consume the carcass until $17 \mathrm{~h} 52$, after which the carcass was discarded. The chimpanzee holding the carcass changed eight times (Fig. 2), and several other chimpanzees ate some of the meat. All transfers of the carcass were peaceful: the former possessor left it on the tree branch and the next simply retrieved it. In total, the chimpanzees held the carcass for $5 \mathrm{~h}$ and $37 \mathrm{~min}$, with an adult female, Cynthia, holding it for the longest time, $2 \mathrm{~h}$ and $44 \mathrm{~min}$.

As they were eating the meat in the tree, the return (or continuous presence) of the leopard was indicated by several observations. First, at $13 \mathrm{~h} 33$, some chimpanzees in the same $P$. microcarpa tree but away from the meat-eating cluster emitted waa barks while looking down at the ground toward the east. Simultaneously, red-tailed monkeys (Cercopithecus ascanius) also gave alarm calls from approximately $20 \mathrm{~m}$ away. These monkeys usually maintain silence when chimpanzees are in their proximity, but emit noisy alarm calls when they encounter leopards. After 1 minute, waa barks could be heard again. At 14h07, a tracker from one of the tourist camps witnessed a leopard in the bush to the west of the meat-eating cluster, which then moved northward. Several waa barks were emitted by the chimpanzees in the tree, apparently directed toward the ground. At 14h51, waa barks could be heard from a few dozen meters distance toward the north, and several chimpanzees hurried down and went northward, into the bush. Other chimpanzees remained in the tree and continued to eat the meat. Later, at $17 \mathrm{~h} 21$, we found fresh leopard scat in the nearby bush, $10 \mathrm{~m}$ away from the P. microcarpa tree.

On this day, we observed a total of 21 chimpanzees $(1,10,10$ : numbers of adult males, adult females, and immatures, respectively), of which three $(0,2,1)$ were observed only in the morning. Thus, a total of $18(1,8,9)$ chimpanzees were present near the scavenging area, of which $10(1,4,5)$ were present from the beginning of the episode, and the remaining $8(0,4,4)$ arrived after the primary chimpanzees had begun to eat the meat.

\subsection{The scavenged prey}

After the chimpanzees had completely abandoned the duiker carcass, M.N. retrieved it and brought it to the research camp for closer observation. The intestines, right hind leg, and left foreleg had been bitten and eaten by the chimpanzees, but the other parts were mostly intact (Fig. 1b). The head and body together were $570 \mathrm{~mm}$ in length, and the remaining body was $2.20 \mathrm{~kg}$. The length was within the normal range of lengths found in adult male blue duikers (Wilson, 2001, cited in Hart and Kingdon, 2013). A 570-mm duiker can be estimated to weigh 3.18 or $4.39 \mathrm{~kg}$, depending on whether the calculation 
uses one or the other of two length-weight relationships reported in the literature. Thus, $0.98 \mathrm{~kg}(30.8 \%)$ or $2.19 \mathrm{~kg}(49.9 \%)$ was lost (either eaten or discarded) from the duiker carcass before we procured the body. The chimpanzees discarded some bone fragments (after biting and sucking the marrow) and the lungs, if not more, but we assume that they ate most of the lost parts (muscles and intestines).

\subsection{Encounters with animal carcasses and scavenging}

In the case reported here, the Mahale chimpanzees did not flee from the leopard, although they were aware of its presence. To assess situations in which chimpanzees scavenge the meat of animal carcasses in a quantitative way, we compiled a list of cases of encounters with animal carcasses in Mahale (Table 1). Between 1980 and 2017, 49 such cases were recorded, 18 (36.7\%) of which involved scavenging. Furthermore, 13 cases likely involved leopards, as indicated by wounds on the carcass and roars heard in the vicinity.

The 49 cases of encounters included carcasses of nine bushbucks (Tragelaphus scriptus), eight blue duikers (Philantomba monticola), seven red colobus monkeys (Procolobus rufomitratus), five bushpigs (Potamochoerus larvatus), three red-tailed monkeys (Cercopithecus ascanius), three mongooses (Herpestidae), two aardvarks (Orycteropus afer), one leopard (Panthera pardus), one yellow baboon (Papio cynocephalus), one genet (Genetta sp.), one fruit bat (Pteropodidae), one porcupine (possibly Hystrix africaeaustralis), one squirrel (Sciuridae), one unknown small mammal, four avian species, and one unidentified river fish. The first five species and the squirrel were considered to be food species for chimpanzees.

Species that were usually consumed during chimpanzee hunting were more likely to be scavenged than those that were not usually consumed ( $p=0.039$; Fig. 3a). Fresh carcasses were also more likely to be consumed than older ones ( $p=0.019$; Fig. $3 b)$. When both of these conditions were met (i.e., the carcass was of a familiar prey species and fresh), the chimpanzees scavenged in 9 out of 12 cases (75.0\%). However, the scavenging ratio did not significantly differ between cases with and without evidence of leopard involvement $(\mathrm{p}=1.00$; Fig. $3 \mathrm{c})$. Of the 18 cases where chimpanzees actually ate the carcasses, $88.9 \%$ (16/18) were carcasses of chimpanzees' food species, $76.9 \%$ (10/13, five were unknown) were fresh, and in $29.4 \%$ (5/17, one was unknown), the presence of a leopard was indicated. 
Table 1. Cases of encounters with animal carcasses (excluding chimpanzee carcasses) by the Mahale chimpanzees

\begin{tabular}{|c|c|c|c|c|c|c|c|c|}
\hline ID & $\begin{array}{l}\text { Date } \\
(\mathbf{y} / \mathbf{m} / \mathbf{d})\end{array}$ & Species of the carcass & Food $^{\text {a }}$ & Fresh $^{b}$ & Leopard ${ }^{c}$ & Scavenge & Notes & References/Observers $^{\mathrm{d}}$ \\
\hline 1 & $1980 / 10 / 7$ & blue duiker (female) & + & - & - & + & $\begin{array}{l}\text { Died of disease or shock? Experimentally presented to chimpanzees by } \\
\text { humans. }\end{array}$ & $\begin{array}{l}\text { Hasegawa et al., 1983; Takahata et } \\
\text { al., } 1984 \text { (case } 38 \text { ) }\end{array}$ \\
\hline 2 & $1981 / 8 / 27$ & blue duiker (female) & + & + & + & + & $\begin{array}{l}\text { Wound at throat. Internal organs experimentally presented to chimpanzees by } \\
\text { humans. }\end{array}$ & Hasegawa et al., 1983 \\
\hline 3 & $1981 / 9 / 30$ & bushbuck (juvenile) & + & + & + & + & Leopard roar heard the night before. & $\begin{array}{l}\text { Hasegawa et al., 1983; Takahata et } \\
\text { al., } 1984 \text { (case 23); Nishida, } 2012\end{array}$ \\
\hline 4 & $1981 / 11 / 18$ & bushbuck (adult male) & + & - & $\mathrm{N} / \mathrm{A}$ & + & $\begin{array}{l}\text { Although Hasegawa et al. (1983) stated "The killer is very likely to have been } \\
\text { a leopard," according to Y. Takahata, there was no strong evidence to support } \\
\text { it. }\end{array}$ & $\begin{array}{l}\text { Hasegawa et al., 1983; Takahata et } \\
\text { al., } 1984 \text { (case 55) }\end{array}$ \\
\hline 5 & $1983 / 10 / 19$ & red-tailed monkey & + & N/A & - & + & & Uehara et al., 1992; Nishida, 1994 \\
\hline 6 & $1985 / 10 / 27$ & bushpig (adult) & + & + & + & - & Chimpanzees slightly tense. & Nishida, 1994, 2012 \\
\hline 7 & $1990 / 1 / 15$ & blue duiker (female) & + & + & - & + & Killed by a raptor? & $\begin{array}{l}\text { Uehara et al., 1992; Nishida, 1994, } \\
2012\end{array}$ \\
\hline 8 & $1991 / 5 / 17$ & blue duiker & + & + & - & + & May have been hunted by chimpanzees or scavenged. & Unpublished MMCRP records \\
\hline 9 & $1992 / 7 / 14$ & bushbuck (adult) & + & $\mathrm{N} / \mathrm{A}$ & - & + & & Hosaka et al., 2001 \\
\hline 10 & $1992 / 8 / 18$ & red colobus (adult female) & + & + & - & + & & $\begin{array}{l}\text { Nishida, 1994; Hosaka et al., 2001; } \\
\text { Nishida, } 2012\end{array}$ \\
\hline 12 & $1993 / 7 / 10$ & bushbuck (subadult) & + & + & + & + & $\begin{array}{l}\text { Cached by a leopard? Leopard roars heard the previous evening. All } \\
\text { chimpanzees remained silent while eating. }\end{array}$ & Hosaka et al., 2001 \\
\hline 13 & $1993 / 9 / 23$ & bushbuck & + & - & - & - & Chimpanzees showed almost no interest. & K.H. \\
\hline 14 & $1994 / 1 / 6$ & bushbuck & + & - & - & - & Chimpanzees emitted wraa calls and huus. & K.H. \\
\hline 15 & $1994 / 7 / 18$ & bushbuck & + & $\mathrm{N} / \mathrm{A}$ & - & - & Chimpanzees showed interest. & M.N. \\
\hline 16 & $1994 / 7 / 18$ & red colobus & + & N/A & - & - & Chimpanzees showed interest. & M.N. \\
\hline 17 & $1997 / 1 / 5$ & $\begin{array}{l}\text { small river fish (species } \\
\text { unidentified) }\end{array}$ & - & - & - & - & Chimpanzees showed interest. & M.N. \\
\hline 18 & $1997 / 9 / 15$ & bushpig & + & - & - & - & Chimpanzees showed fear (watching from a distance, none approached). & N.I. \\
\hline 19 & $1999 / 8 / 10$ & red colobus & + & $\mathrm{N} / \mathrm{A}$ & + & + & & Hosaka, 2015 \\
\hline 20 & $1999 / 8 / 30$ & leopard & - & + & + & - & $\begin{array}{l}\text { Claw-like wound was seen on the neck. Chimpanzees showed interest and fear, } \\
\text { attacked, and investigated. }\end{array}$ & $\begin{array}{l}\text { Nishida and Zamma, 2000; Nishida } \\
\text { et al., 2010; Nishida, } 2012\end{array}$ \\
\hline 21 & $1999 / 11 / 18$ & bushpig (piglet) & + & + & - & - & Trapped in vines on the ground. Chimpanzees showed interest and investigated. & K.Z. \\
\hline 22 & 2001/1/17 & blue duiker (adult) & + & + & - & + & Killed by an ambush predator (ratel or civet?). & Hosaka and Ihobe, 2015 \\
\hline 25 & 2001/11/8 & $\begin{array}{l}\text { mongoose (species } \\
\text { unidentified, immature) }\end{array}$ & - & N/A & - & - & A chimpanzee played with it. & Unpublished MMCRP records \\
\hline
\end{tabular}




\begin{tabular}{|c|c|c|c|c|c|c|c|c|}
\hline 26 & $2001 / 12 / 25$ & augur buzzard & - & N/A & - & - & Chimpanzees showed caution (waa, huu) and interest. & M.N., M.S. \\
\hline 27 & 2002/9/19 & red colobus & + & - & - & - & Chimpanzees picked it up but soon discarded it. & H.N. \\
\hline 28 & $2002 / 9 / 22$ & red colobus & + & - & - & - & Chimpanzees picked it up. & H.N. \\
\hline 29 & $2002 / 10 / 7$ & red colobus (adult) & + & + & - & + & Probably discarded by another chimpanzee. & M.S., H.N., T.N. \\
\hline 30 & $2002 / 11 / 3$ & $\begin{array}{l}\text { squirrel (species } \\
\text { unidentified) }\end{array}$ & + & $\mathrm{N} / \mathrm{A}$ & - & + & & Unpublished MMCRP records \\
\hline 31 & $2004 / 8 / 10$ & bird (Merops sp.?) & - & N/A & - & - & A chimpanzee picked it up, sniffed it, and then discarded it. & Unpublished MMCRP records \\
\hline 32 & $2005 / 8 / 17$ & aardvark & - & + & + & - & Chimpanzees showed interest and fear. & Hosaka et al., 2014 \\
\hline 33 & $2005 / 9 / 1$ & bushbuck & + & - & - & - & Chimpanzees showed no notable responses. & K.H. \\
\hline 34 & $2005 / 9 / 4$ & aardvark & - & - & - & - & Chimpanzees showed interest and fear. & Hosaka et al., 2014 \\
\hline 35 & 2005/11/1 & $\begin{array}{l}\text { bird (black kite? species } \\
\text { unidentified) }\end{array}$ & - & + & - & + & Died of fatigue? & M.N. \\
\hline 36 & $2005 / 12 / 11$ & bushbuck & + & - & + & - & $\begin{array}{l}\text { The carcass was already partially eaten when chimpanzees encountered it. } \\
\text { Chimpanzees showed caution and interest and grabbed a leg. }\end{array}$ & T.S. \\
\hline 37 & $2007 / 12 / 19$ & porcupine & - & - & + & - & Chimpanzees sniffed. & T.Ms. \\
\hline 38 & 2008/9/11 & $\begin{array}{l}\text { genet (species } \\
\text { unidentified) }\end{array}$ & - & - & - & - & Chimpanzees investigated and carried. & M.N. \\
\hline 39 & $2008 / 10 / 16$ & $\begin{array}{l}\text { fruit bat (species } \\
\text { unidentified) }\end{array}$ & - & - & - & - & Chimpanzees sniffed. & M.N. \\
\hline 40 & $2009 / 7 / 22$ & $\begin{array}{l}\text { mongoose (species } \\
\text { unidentified) }\end{array}$ & - & + & - & - & A chimpanzee carried it for a while. & T.Ms. \\
\hline 41 & $2009 / 7 / 26$ & $\begin{array}{l}\text { mongoose (species } \\
\text { unidentified) }\end{array}$ & - & N/A & - & - & Two chimpanzees carried it for a while in sequence. & T.Ms. \\
\hline 42 & $2009 / 9 / 8$ & red-tailed monkey & + & N/A & - & - & A chimpanzee carried it for a while. & K.H. \\
\hline 43 & $2009 / 9 / 29$ & bushpig (adult) & + & - & - & - & Chimpanzees showed interest and fear (wraa). & M.N. \\
\hline 44 & $2011 / 3 / 16$ & bushpig (adult) & + & - & + & - & The cervical region was already eaten. Chimpanzees showed interest and fear. & T.Mm. \\
\hline 45 & 2011/11/17 & $\begin{array}{l}\text { small mammal (species } \\
\text { unidentified) }\end{array}$ & $\mathrm{N} / \mathrm{A}$ & - & - & - & Chimpanzees showed interest. & M.N. \\
\hline 46 & $2011 / 12 / 5$ & blue duiker & + & - & - & + & Probably discarded by another chimpanzee. A chimpanzee gnawed on it. & M.N. \\
\hline 47 & $2015 / 8 / 29$ & red-tailed monkey (adult) & + & + & - & - & Probably killed by a raptor. Some chimpanzees smelled it but most ignored. & K.H. \\
\hline 48 & $2016 / 9 / 4$ & red colobus & + & - & - & - & Chimpanzees smelled. & M.N. \\
\hline 49 & 2016/11/15 & blue duiker (adult male) & + & + & + & + & A leopard sighted twice. & $\begin{array}{l}\text { M.N., M.Y. The case shown in this } \\
\text { study. }\end{array}$ \\
\hline
\end{tabular}

${ }^{a}$ Whether the observed carcass was of a species commonly eaten during hunting by chimpanzees $(+)$ or not $(-)$. See methods for the definition.

${ }^{\mathrm{b}}$ Whether the observed carcass was fresh $(+)$ or not $(-)$. See methods for the definition.

${ }^{c}$ Whether evidence suggestive of the involvement of a leopard was found $(+)$ or not $(-)$. See methods for the definition.

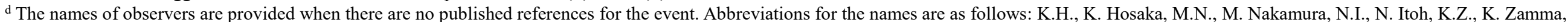

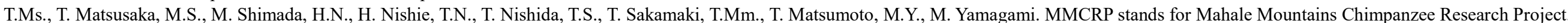



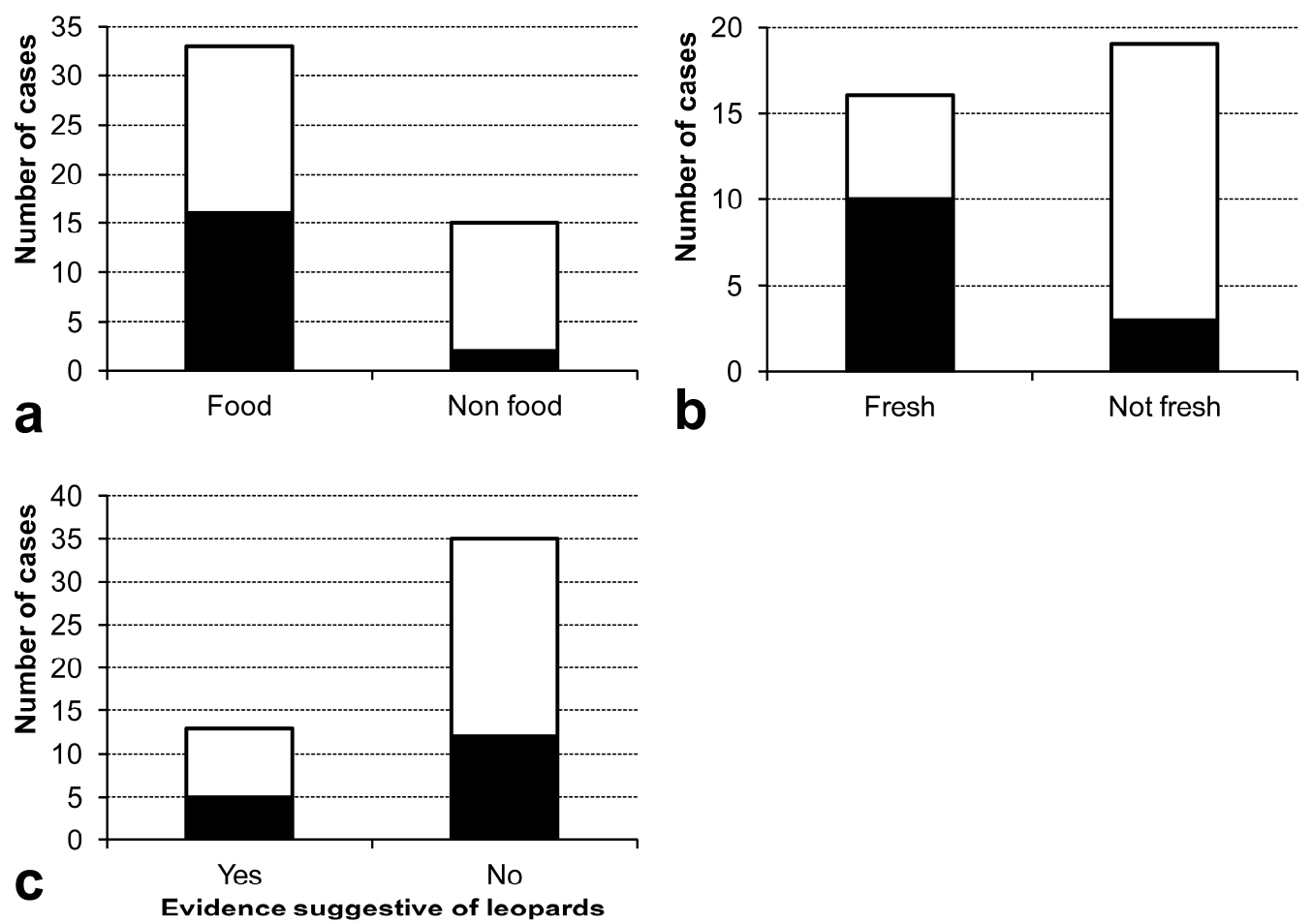

Figure 3. Chimpanzees' encounters with (a) carcasses of food/non-food species, (b) fresh/nonfresh carcasses, and (c) carcasses with evidence suggestive of a leopard's presence and without such evidence

Black indicates cases in which the meat was eaten.

\section{Discussion}

\subsection{Do chimpanzees avoid confronting a carnivore?}

This is the first report to confirm that wild chimpanzees can obtain a kill from a potential predator, namely, a leopard, and scavenge meat from that kill even in the vicinity of the predator. This observation suggests that the current understanding of the hominid-carnivore relationship should be revised. Boesch (2009) emphasized the importance of leopards in the evolution of the social structure, cooperation, and intellectual behavior of chimpanzees because leopards are life-threatening predators to them. However, this does not imply that chimpanzees must always be fearful and helpless victims, avoiding leopards whenever possible. For instance, in Mahale, chimpanzees attacked a leopard den and killed a cub (Hiraiwa-Hasegawa et al., 1986), and other, similar cases have been reported at Taï (Boesch, 2009). Thus, chimpanzees can also be dangerous to leopards in certain situations. Here, we have added an additional dimension to this complex hominid-carnivore relationship, specifically, competition over meat. According to our observations, the leopard likely killed the duiker just before the chimpanzees arrived, as suggested by continued bleeding of the duiker's throat wound. Several chimpanzees rushed to the nearby tree and barked 
loudly, and we conclude from this that the leopard was deterred and left its kill in the bush and retreated while the chimpanzees obtained the carcass. The leopard appears not to have given up its prey easily, as it either returned several times or remained in the vicinity for some time.

Importantly, although the leopard was nearby, the chimpanzees descended to the ground to obtain the carcass and remained in the same tree. Because they frequently emitted waa barks, they probably recognized the continued presence of the leopard. They did not show excessive fear or panic, nor did they attempt to flee, even though there was only one adult male chimpanzee. Waa barks in this case seemed to have functioned to intimidate a potentially dangerous carnivore (Zuberbühler et al., 1999) instead of alerting conspecifics to flee. Multiple chimpanzees shouting loudly may be enough to chase away a leopard or at least deter it from approaching. This conclusion is consistent with previous data that were collected from a radio-tracked adult female leopard that avoided nearby parties of chimpanzees and moved away from them upon hearing their vocalizations (Zuberbüler and Jenny, 2002). Undoubtedly, leopards are potential predators of hominids: they have been documented to eat chimpanzees (Boesch, 1991; Nakazawa et al., 2013) and humans (Treves and Naughton-Treves, 1999; Hart and Sussman, 2005). However, because a leopard is about the same size as a chimpanzee and is solitary, hominids may be able to overcome the fear of confrontation with leopards if they are in a group, and it is daylight.

\subsection{Is chimpanzee scavenging rare?}

Chimpanzee scavenging is often regarded as rare (Watts, 2008). However, this view should be reconsidered in light of the fact that leopards are locally extinct at many longterm chimpanzee study sites (Nakazawa et al., 2013), including Ngogo, from which Watts (2008) collected his own data supporting this assertion. If there are no sympatric large carnivores, chimpanzees have no chance to encounter their kills, and as a consequence, they cannot scavenge these nonexistent carcasses. This would decrease the overall opportunity for scavenging. Because at least seven leopards are present in the study area of Mahale (N.N., unpublished data), our dataset provides a better approach to understanding scavenging among omnivorous hominids.

Although exposure to scavenging situations is more likely in our study area, our larger dataset also showed that scavenging by chimpanzees is nevertheless not very common. Furthermore, chimpanzees do not actively seek carcasses to scavenge meat. Even at Mahale, where the density of sympatric leopards is high, chimpanzees appear to encounter animal carcasses only rarely (49 cases in 37 years) relative to encounters with live animal prey. Because Mahale chimpanzees killed at least 254 prey animals over 13 
years (Hosaka, 2015), their encounter rate for live animals appears to be roughly an order of magnitude greater than the rate for dead animals. Of course, the number of cases listed in Table 1 is likely underestimated because we only counted cases observed by humans. Nevertheless, we assume that chimpanzees encounter carcasses only a few to several times per year because there are fewer large herbivore species in Mahale than on the savanna. The humidity and abundant insects present in the forest may also hasten the decomposition of carcasses, thus further reducing the availability of carcasses suitable for scavenging (see review by DeVault et al., 2003 for factors affecting carcass availability). However, although opportunities for encounters are rare, when chimpanzees do find fresh carcasses of familiar prey species, they are commonly observed to practice scavenging.

Researchers working in Mahale have repeatedly proposed that the chimpanzees living there scavenge prey from leopards (Hasegawa et al., 1983; Nishida, 1994; Hosaka, 2015). However, no direct evidence has previously appeared that chimpanzees confronted leopards in such cases, possibly because both species must be habituated to human observers before such cases can be recorded. In the case presented here, we assumed that the leopard had been accustomed somehow to human presence. For the past few years, a leopard named Pazu (estimated to have been born in 2014, sex unknown but probably female) has been frequently observed near the researchers' camp. Pazu has been seen remaining calm even in the presence of humans on certain occasions and was once observed eating a rat in the camp. Although we could not confirm the identity of the leopard in this case, the observations we present here were recorded within the home range of Pazu, as confirmed by camera traps (N.N., unpublished data).

\subsection{What makes scavenging possible?}

In our case, the prey was still bleeding when it was first observed and was hence assumed to have been scavenged immediately following its death. The freshness of meat is an important factor determining whether chimpanzees will eat it, as the presence of harmful bacteria in meat increases over time after death (Smith et al., 2015). Contemporary human hunter-gatherers have scavenged even half-rotten meat in the forest (Mitsuo Ichikawa, personal communication), and they often ensure safe consumption by boiling the meat for a long period for detoxication. However, for chimpanzees, who eat meat raw, it may be adaptive simply to avoid such halfdecomposed meat. In the one case in which an apparently fresh carcass was observed not to be consumed (Table 1, ID 6), Nishida (1994) initially suggested that anxiety over the return of the leopard may have been the reason that the carcass was not eaten. However, he later rejected this possibility because the chimpanzees took over 10 
minutes to decide to abandon it (Nishida, 2012). Our case showed that the return of the leopard does not always result in the abandonment of the carcass of the leopard's prey. Among the 10 fresh carcasses scavenged by chimpanzees (Table 1), 4 exhibited evidence of leopard involvement. This proportion was nearly identical for cases when fresh carcasses were not consumed (i.e., in three out of seven cases, there was evidence of leopard presence). Although the number of cases observed is too few to allow firm conclusions to be drawn, this also indicates that the avoidance of scavenging fresh carcasses by chimpanzees cannot simply be regarded as the result of the likelihood of the leopard's return.

Confronting large carnivores is, of course, risky, but such risks may be reduced by increased numbers of participants and aimed throwing (Bickerton and Szathmáry, 2011). In our case, 10 chimpanzees were initially present, and an additional 8 joined later. Because the leopard was solitary and relatively smaller than other big cats, the potential risk of confrontation with it may have been reduced by there being many individual chimpanzees involved. On the contrary, aimed throwing (previously reported in chimpanzees: Goodall, 1964; Kortlandt, 1967; Nishida et al., 2012) was not observed in our case, probably because the leopard was hidden in dense undergrowth. Thus, although Számadó (2010) argued that relatively modern weapons, such as the bow and arrow, are essential for confrontation with carnivores, our observations appear to contradict his argument. Modern weapons are of course useful, especially against larger carnivores, but they may nevertheless not be requisite because modern humans sometimes drive carnivores from kills using only stones or long sticks, particularly when they do so cooperatively (Treves and Naughton-Treves, 1999).

\subsection{Implications to early hominin scavenging}

In the early stages of hominin scavenging, the targets may not have been exclusively large herbivores (cf. Cavallo and Blumenschine, 1989). Our observation suggests that chimpanzee-sized hominins could have confronted a solitary leopard-sized carnivore even without refined projectile weapons if they significantly outnumbered it and were producing loud vocalizations. Even if hominins had this potential, the availability of opportunities for scavenging could have been limited also by the paleoenvironments. One study reported that, for early Pleistocene hominins, the differences among environments resulted in large differences in the availability of scavenging opportunities (Turner, 1998). In wetter habitats, the supply of animal carcasses available for scavenging is less predictable than it is in drier ones (Tappen, 2001). We argue that the rarity of chimpanzee scavenging may be due to an initially low availability of such opportunities in the forest environment. 
Therefore, the common ancestors of chimpanzees and humans, when they were still inhabiting a forest environment, may have opportunistically scavenged and sometimes deprived carnivores of their kills, in addition to capturing small animals. Collective foraging and loud vocalizations to intimidate carnivores while recruiting more conspecifics might have been sufficient to achieve this. When the hominin lineage migrated to drier habitats, such as woodlands and the savanna, they may have met with an increased number of opportunities to encounter carcasses, especially those of large herbivores. Further, if they became able to recognize their ability to exploit other predators' prey and actively sought out such situations, their opportunities to obtain meat through scavenging might have increased even further. In this case, our ancestors could have exploited such opportunities and incorporated scavenged meat into their daily diet by using confrontational scavenging as a regular and intentional behavior. If early Pleistocene hominins exhibited this behavioral shift, it might have been attained parallel to changes in social behavior including elaborated forms of cooperation and a communication system, as it would have been advantageous for competing over meat against carnivores, who continued to be their potential predators.

\section{Acknowledgments}

We thank the Tanzanian Commission for Science and Technology, Tanzania Wildlife Research Institute, and Tanzania National Parks for their permission to conduct research at Mahale. We also thank the associate editor and anonymous reviewers for constructive comments on an earlier version of the manuscript. This work was supported by MEXT/JSPS KAKENHI Grant Numbers \#4903 (JP17H06381) and JP15H04429.

\section{References}

Ardrey, R., 1961. African Genesis: A Personal Investigation into the Animal Origins and Nature of Man. Dell Publishing, New York.

Baldus, R.D., 2006. A man-eating lion (Panthera leo) from Tanzania with a toothache. European Journal of Wildlife Research 52, 59-62.

Benjamini, Y., Hochberg, Y., 1995. Controlling the false discovery rate: a practical and powerful approach to multiple testing. Journal of the Royal Statistical Society Series B 57, 289-300.

Bickerton, D., 2009. Adam's Tongue: How Humans Made Language, How Language Made Humans. Hill and Wang, New York.

Bickerton, D., Szathmáry, E., 2011. Confrontational scavenging as a possible source for language and cooperation. BMC Evolutionary Biology 11, 261. 
Blumenschine, R.J., 1987. Characteristics of an early hominid scavenging niche. Current Anthropology 28, 383-407.

Blumenschine, R.J., 1995. Percussion marks, tooth marks, and experimental determinations of the timing of hominid and carnivore access to long bones at FLK Zinjanthropus, Olduvai Gorge, Tanzania. Journal of Human Evolution 29, $21-51$

Blumenschine, R.J., Prassack, K.A., Kreger, C.D., Pante, M.C., 2007. Carnivore toothmarks, microbial bioerosion, and the invalidation of Domínguez-Rodrigo and Barba's (2006) test of Oldowan hominin scavenging behavior. Journal of Human Evolution 53, 420-426.

Boesch, C., 1991. The effects of leopard predation on grouping patterns in forest chimpanzees. Behaviour 117, 220-242.

Boesch, C., 2009. The Real Chimpanzee: Sex Strategies in the Forest. Cambridge University Press, Cambridge.

Boesch, C., Boesch-Achermann, H., 2000. The Chimpanzees of the Taï Forest: Behavioral Ecology and Evolution. Oxford University Press, Oxford.

Brand, C., Eguma, R., Zuberbühler, K., Hobaiter, C., 2014. First report of prey capture from human laid snare-traps by wild chimpanzees. Primates 55, 437-440.

Bunn, H.T., 2001. Hunting, power scavenging, and butchering by Hadza foragers and by Plio-Pleistocene Homo. In: Stanford, C.B., Bunn, H.T. (Eds.), Meat-Eating and Human Evolution. Oxford University Press, Oxford, pp. 199-218.

Bunn, H.T., Ezzo, J.A., 1993. Hunting and scavenging by Plio-Pleistocene hominids: nutritional constraints, archaeological patterns, and behavioral implications. Journal of Archaeological Science 20, 365-398.

Bunn, H.T., Gurtov, A.N., 2014. Prey mortality profiles indicate that early Pleistocene Homo at Olduvai was an ambush predator. Quaternary International 322, 44 53.

Bunn, H.T., Kroll, E.M., 1986. Systematic butchery by Plio/Pleistocene hominids at Olduvai Gorge, Tanzania. Current Anthropology 27, 431-452.

Cavallo, J.A., Blumenschine, R.J., 1989. Tree-stored leopard kills: expanding the hominid scavenging niche. Journal of Human Evolution 18, 393-399.

Dart, R.A., 1953. The predatory transition from ape to man. International Anthropological and Linguistic Review 1(4).

DeVault, T.L., Rhodes, O.E., Shivik, J.A., 2003. Scavenging by vertebrates: behavioral, ecological, and evolutionary perspectives on an important energy transfer pathway in terrestrial ecosystems. Oikos 102, 225-234. 
Domínguez-Rodrigo, M., Barba, R., 2006. New estimates of tooth marks and percussion marks from FLK Zinj, Olduvai Gorge (Tanzania): The carnivore-hominidcarnivore hypothesis falsified. Journal of Human Evolution 50, 170-194.

Domínguez-Rodrigo, M., Barba, R., 2007. Five more arguments to invalidate the passive scavenging version of the carnivore-hominid-carnivore model: a reply to Blumenschine et al. (2007a). Journal of Human Evolution 53, 427-433.

Domínguez-Rodrigo, M., Bunn, H.T., Yravedra, J., 2014. A critical re-evaluation of bone surface modification models for inferring fossil hominin and carnivore interactions through a multivariate approach: application to the FLK Zinj archaeofaunal assemblage (Olduvai Gorge, Tanzania). Quaternary International 322-323, 32-43.

Gandini, G., Baldwin, P.J., 1978. An encounter between chimpanzees and a leopard in Senegal. Carnivore 1, 107-109.

Goodall, J., 1964. Tool-using and aimed throwing in a community of free-living chimpanzees. Nature 28, 1264-1266.

Hart, D., Sussman, R.W., 2005. Man the Hunted: Primates, Predators, and Human Evolution. Westview Press, New York.

Hart, J.A., Kingdon, J., 2013. Philantomba monicola blue duiker. In: Kingdon, J., Hoffmann, M. (Eds.), Mammals of Africa Vol. VI: Pigs, Hippopotamuses, Chevrotain, Giraffes, Deer and Bovids. Bloomsbury, London, pp. 228-234.

Hasegawa, T., Hiraiwa, M., Nishida, T., Takasaki, H., 1983. New evidence on scavenging behavior in wild chimpanzees. Current Anthropology 24, 231-232.

Hiraiwa-Hasegawa, M., Byrne, R.W., Takasaki, H., Byrne, J.M.E., 1986. Aggression toward large carnivores by wild chimpanzees of Mahale Mountains National Park, Tanzania. Folia Primatologica 47, 8-13.

Hosaka, K., 2015. Hunting and food sharing. In: Nakamura, M., Hosaka, K., Itoh, N., Zamma, K. (Eds.), Mahale Chimpanzees: 50 Years of Research. Cambridge University Press, Cambridge, pp. 274-290.

Hosaka, K., Ihobe, H., 2015. Interspecific relationships. In: Nakamura, M., Hosaka, K., Itoh, N., Zamma, K. (Eds.), Mahale Chimpanzees: 50 Years of Research. Cambridge University Press, Cambridge, pp. 213-224.

Hosaka, K., Nishida, T., Hamai, M., Matsumoto-Oda, A., Uehara, S., 2001. Predation of mammals by the chimpanzees of the Mahale Mountains, Tanzania. In: Galdikas, B.M.F., Briggs, N.E., Sheeran, L.K., Shapiro, G.L., Goodall, J. (Eds.), All Apes Great and Small Vol I: African Apes. Kluwer Academic/Plenum, New York, pp. 107-130. 
Hosaka, K., Inoue, E., Fujimoto, M., 2014. Responses of wild chimpanzees to fresh carcasses of aardvark (Orycteropus afer) in Mahale. Pan Africa News 21, 1922.

Izawa, K., Itani, J., 1966. Chimpanzees in Kasakati Basin, Tanganyika: (I) ecological study in the rainy season 1963-1964. Kyoto University African Studies 1, 73156.

Kennedy, G.E., 2005. From the ape's dilemma to the weanling's dilemma: early weaning and its evolutionary context. Journal of Human Evolution 48, $123-$ 145.

Kerbis Peterhans, J.C., Gnoske, T.P., 2001. The science of 'man-eating' among lions Panthera leo with a reconstruction of the natural history of the 'man-eaters of Tsavo'. Journal of East African Natural History 90, 1-40.

Klailova, M., Casanova, C., Henschel, P., Lee, P., Rovero, F., Todd, A., 2013. Nonhuman predator interactions with wild great apes in Africa and the use of camera traps to study their dynamics. Folia Primatologica 83, 312-328.

Kortlandt, A., 1967. Experimentation with chimpanzees in the wild. In: Neue Ergebnisse der Primatologie. Fischer, Stuttgart, pp. 208-224.

van Lawick-Goodall, J., 1968. The behaviour of free-living chimpanzees in the Gombe Stream Reserve. Animal Behaviour Monographs 1, 161-311.

Lee, R.B., De Vore, I. (Eds.), 1968. Man the Hunter. Aldine Transaction, New Brunswick.

McLester, E., Stewart, F.A., Piel, A.K., 2016. Observation of an encounter between African wild dogs (Lycaon pictus) and chimpanzees (Pan troglodytes schweinfurthii) in the Issa Valley, Tanzania. African Primates 11, 27-36.

Moleón, M., Sánchez-Zapata, J.A., Margalida, A., Carrete, M., Owen-Smith, N., Donázar, J.A., 2014. Humans and scavengers: the evolution of interactions and ecosystem services. BioScience 64, 394-403.

Morris, K., Goodall, J., 1977. Competition for meat between chimpanzees and baboons of the Gombe National Park. Folia Primatologica 28, 109-121.

Muller, M.N., Mpongo, E., Stanford, C.B., Boehm, C., 1995. A note on scavenging by wild chimpanzees. Folia Primatologica 65, 43-47.

Nakamura, M., Hosaka, K., Itoh, N., Zamma, K. (Eds.), 2015. Mahale Chimpanzees: 50 Years of Research. Cambridge University Press, Cambridge.

Nakazawa, N., Hanamura, S., Inoue, E., Nakatsukasa, M., Nakamura, M., 2013. A leopard ate a chimpanzee: the first evidence from East Africa. Journal of Human Evolution 65, 334-337. 
Nishida, T., 1968. The social group of wild chimpanzees in the Mahali Mountains. Primates 9, 167-224.

Nishida, T., 1994. Review of recent findings on Mahale chimpanzees: implications and future research directions. In: Wrangham, R.W., McGrew, W.C., de Waal, F.B.M., Heltne, P.G. (Eds.), Chimpanzee Cultures. Harvard University Press, Cambridge, MA, pp. 373-396.

Nishida, T., 2012. Chimpanzees of the Lakeshore: Natural History and Culture at Mahale. Cambridge University Press, Cambridge.

Nishida, T., Zamma, K., 2000. [Responses to a fresh leopard carcass by the wild chimpanzees of Mahale.] Program \& Abstracts of the 37th Annual Congress of the Japanese Association for African Studies, Faculty of International Studies, Hiroshima City University, Hiroshima, p. 56, in Japanese.

Nishida, T., Zamma, K., Matsusaka, T., Inaba, A., McGrew, W.C., 2010. Chimpanzee Behavior in the Wild: An Audio-Visual Encyclopedia. Springer, Tokyo.

Nishida, T., McGrew, W.C., Marchant, L.F., 2012. Wild chimpanzees at Mahale are not manually lateralised for throwing. Pan Africa News 19, 21-23.

Nishie, H., 2018. Leopards attempted to hunt wild chimpanzees at Mahale. Pan Africa News 25, 25-26.

O’Connell, J.F., Hawkes, K., Jones, N.B., 1988. Hadza scavenging: Implications for Plio/Pleistocene hominid subsistence. Current Anthropology 29, 356-363.

O’Connell, J.F., Hawkes, K., Lupo, K.D., Jones, N.B., 2002. Male strategies and PlioPleistocene archaeology. Journal of Human Evolution 43, 831-872.

Pante, M.C., Blumenschine, R.J., Capaldo, S.D., Scott, R.S., 2012. Validation of bone surface modification models for inferring fossil hominin and carnivore feeding interactions, with reapplication to FLK 22, Olduvai Gorge, Tanzania. Journal of Human Evolution 63, 395-407.

Pante, M.C., Scott, R.S., Blumenschine, R.J., Capaldo, S.D., 2015. Revalidation of bone surface modification models for inferring fossil hominin and carnivore feeding interactions. Quaternary International 355, 164-168.

Pierce, A.H., 2009. An encounter between a leopard and a group of chimpanzees at Gombe National Park. Pan Africa News 16, 22-24.

Poirotte, C., Kappeler, P.M., Ngoubangoye, B., Bourgeois, S., Moussodji, M., Charpentier, M.J., 2016. Morbid attraction to leopard urine in Toxoplasmainfected chimpanzees. Current Biology 26, R98-R99.

R Core Team, 2017. R: A Language and Environment for Statistical Computing. R Foundation for Statistical Computing, Vienna. 
Schel, A.M., Townsend, S.W., Machanda, Z., Zuberbühler, K., Slocombe, K.E., 2013. Chimpanzee alarm call production meets key criteria for intentionality. PLOS One 8, e76674.

Shipman, P., 1986. Scavenging or hunting in early hominids: theoretical framework and tests. American Anthropologist 88, 27-43.

Smith, A.R., Carmody, R.N., Dutton, R.J., Wrangham, R.W., 2015. The significance of cooking for early hominin scavenging. Journal of Human Evolution 84, 62-70.

Speth, J.D., 1989. Early hominid hunting and scavenging: the role of meat as an energy source. Journal of Human Evolution 18, 329-343.

Strauss, B., 1972. Leakey views ancient man: fossils vindicate Darwin theory. The Cornell Daily Sun, Feb. 23, 1972.

Suzuki, A., 1971. Carnivority and cannibalism observed among forest-living chimpanzees. Journal of the Anthropological Society of Nippon 79, 30-48.

Számadó, S., 2010. Pre-hunt communication provides context for the evolution of early human language. Biological Theory 5, 366-382.

Takahata, Y., Hasegawa, T., Nishida, T., 1984. Chimpanzee predation in the Mahale Mountains from August 1979 to May 1982. International Journal of Primatology 5, 213-233.

Tanaka, J. 1990. [Bushmen: An Ecological Anthropological Study.] Shisaku-sha, Tokyo, in Japanese.

Tappen, M., 2001. Deconstructing the Serengeti. In: Stanford, C.B., Bunn, H.T. (Eds.), Meat-Eating and Human Evolution. Oxford University Press, Oxford, pp. 1332.

Treves, A., Naughton-Treves, L., 1999. Risk and opportunity for humans coexisting with large carnivores. Journal of Human Evolution 36, 275-282.

Tsukahara, T., 1993. Lion eat chimpanzees: the first evidence of predation by lions on wild chimpanzees. American Journal of Primatology 29, 1-11.

Turner, A., 1998. Relative scavenging opportunities for east and south African PlioPleistocene hominids. Journal of Archaeological Science 15, 327-341.

Uehara, S., Nishida, T., Hamai, M., Hasegawa, T., Hayaki, H., Huffman, M.A., Kawanaka, K., Kobayashi, S., Mitani, J.C., Takahata, Y., Takasaki, H., Tsukahara, T., 1992. Characteristics of predation by the chimpanzees in the Mahale Mountains National Park, Tanzania. In: Nishida, T., McGrew, W.C., Marler, P., Pickford, M., de Waal, F.B.M. (Eds.), Topics in Primatology, Vol. 1: Human Origins. University of Tokyo Press, Tokyo, pp. 143-158. 
Watts, D.P., 2008. Scavenging by chimpanzees at Ngogo and the relevance of chimpanzee scavenging to early hominin behavioral ecology. Journal of Human Evolution 54, 125-133.

Yamazaki, K., Bwalya, T., 1999. Fatal lion attacks on local people in the Luangwa Valley, Eastern Zambia. South African Journal of Wildlife Research 29, 19-21.

Zuberbüler, K., Jenny, D., 2002. Leopard predation and primate evolution. Journal of Human Evolution 43, 873-886.

Zuberbühler, K., Jenny, D., Bshary, R., 1999. The predator deterrence function of primate alarm calls. Ethology 105, 477-490. 